\title{
Mechanical properties of woven banana fibre reinforced epoxy composites
}

\begin{abstract}
In this paper, the experiments of tensile and flexural (three-point bending) tests were carried out using natural fibre with composite materials (Musaceae/epoxy). Three samples prepared from woven banana fibre composites of different geometries were used in this research. From the results obtained, it was found that the maximum value of stress in x-direction is 14.14 $\mathrm{MN} / \mathrm{m} 2$, meanwhile the maximum value of stress in y-direction is $3.398 \mathrm{MN} / \mathrm{m} 2$. For the Youngôs modulus, the value of $0.976 \mathrm{GN} / \mathrm{m} 2$ in $\mathrm{x}$-direction and $0.863 \mathrm{GN} / \mathrm{m} 2$ in y-direction were computed. As for the case of three-point bending (flexural), the maximum load applied is $36.25 \mathrm{~N}$ to get the deflection of woven banana fibre specimen beam of $0.5 \mathrm{~mm}$. The maximum stress and Youngôs modulus in x-direction was recorded to be $26.181 \mathrm{MN} / \mathrm{m} 2$ and $2.685 \mathrm{GN} / \mathrm{m} 2$, respectively. Statistical analysis using ANOVA-one way has showed that the differences of results obtained from those three samples are not significant, which confirm a very stable mechanical behaviour of the composites under different tests. This shows the importance of this product and allows many researchers to develop an adequate system for producing a good quality of woven banana fibre composite which maybe used for household utilities.
\end{abstract}

Keyword: Woven banana; Mechanical properties; Epoxy composites; Fibre; Tensile test; Flexural test; ANOVA-one way; F-test 